\title{
Regional melanoma incidence in England, 1996-2006: reversal of north-south latitude trends among the young female population
}

\author{
S.C. Wallingford, ${ }^{1,2}$ R.D. Alston, ${ }^{2}$ J.M. Birch ${ }^{2}$ and A.C. Green ${ }^{1,3}$ \\ ${ }^{1}$ Manchester Academic Health Science Centre, Institute of Inflammation and Repair and ${ }^{2}$ Cancer Research U.K. Paediatric and Familial Cancer Research Group, \\ Institute of Cancer Sciences, Manchester Academic Health Science Centre, University of Manchester, Oxford Road, Manchester M13 9PT, U.K. \\ ${ }^{3}$ Cancer and Population Studies Group, Queensland Institute of Medical Research, Brisbane, Qld 4029, Australia
}

\section{Summary}

\section{Correspondence \\ Sarah C. Wallingford. \\ E-mail: sarah.wallingford@manchester.ac.uk \\ Accepted for publication \\ 2 June 2013 \\ Funding sources \\ This work was supported by a fellowship from the Medical Research Council (grant no. 89912, S.C.W. and A.C.G.) and by Cancer Research U.K. (S.C.W., R.D.A. and J.M.B.). \\ Conflicts of interest \\ None declared.}

DOI $10.1111 /$ bjd. 12460
Background Melanoma incidence often shows an increasing latitudinal gradient from north to south among white European populations.

Objectives To assess emerging regional melanoma incidence patterns in England. Methods All primary invasive cutaneous melanomas diagnosed in England in people aged 10-89 years, in 1996-2006, were ascertained. Age-standardized incidence rates by sex, age and Government Office Region were calculated for the entire population and for the white population only. Rates according to socioeconomic deprivation were further calculated among those aged under 30 years. Regional heterogeneity and latitude and deprivation trends were assessed by Poisson regression and tests for trend.

Results Overall, melanoma incidence in England was highest in the South West (overall, 18.75; white, 19.03 per 100 000) and lowest in London (overall, 8.85; white, 11.22 per 100000$)$. Incidence significantly increased with more southerly latitudes in all white adults aged over 30 years $(\mathrm{P}<0.0001)$, except women aged 30-49 years $(1 \cdot 8 \%, \mathrm{P}=0 \cdot 10)$. However, these north-south latitude trends were reversed in white 10-29 year olds, with sex-specific analyses showing an absence of trend in male subjects $(2.7 \%, \mathrm{P}=0.41)$ and a strong decreasing trend $(-9.8 \%, \mathrm{P}<0.0001)$ in female subjects. The highest rates in the young female population occurred in the North West (5.46 per 100000$)$, and specifically in the second most deprived (5.69 per 100000$)$ and the second most affluent (6.48 per 100 000) groups.

Conclusions Melanoma incidence is high in young people in northern England, including among the moderately deprived, reversing the expected north-south incidence gradients. Prevalent sunbed use in northern England and holiday sun exposure abroad may explain these emerging trends.

\section{What's already known about this topic?}

- Increasing trends in melanoma incidence from north to south have been noted in England and other northern countries.

- Melanoma predominantly affects white, affluent populations; however, neither ethnic groups nor socioeconomic status are uniformly distributed across England.

\section{What does this study add?}

- This study describes a striking reversal in the well-established north-south latitude trend in melanoma incidence among young women in England.

- Incidence was high among young people in northern regions, and particularly among moderately deprived female subjects. 
Over the past several decades rates of cutaneous melanoma have risen rapidly in white populations worldwide, ${ }^{1}$ and sun exposure is widely accepted as the principal environmental cause. $^{2}$ Ambient solar ultraviolet (UV) levels are highly dependent on latitude of residence. Accordingly, north-to-south gradients of increasing melanoma rates have been described in various countries of the northern hemisphere, including England and Wales, ${ }^{3}$ Norway, ${ }^{4-6}$ Canada and the U.S.A. ${ }^{7,8}$ The few studies in northern countries reporting deviations from these trends have mostly been explained by the regional distribution of other melanoma risk factors such as phenotypic traits, income and outdoor recreation. ${ }^{9,10}$

In order to assess recent latitude trends in melanoma incidence in England in light of observed increases in rates across the country, ${ }^{11}$ the current sizeable and unevenly distributed nonwhite population needs to be taken into account. ${ }^{12}$ Because cutaneous melanoma is predominantly a disease of the white skinned, its incidence is intimately linked with ethnicity as a determinant of skin pigmentation. ${ }^{13}$ However, previous studies of melanoma incidence in England have not accounted for the geographical distribution of African and Asian residents who are at innately low risk of melanoma compared with the white population. ${ }^{13,14}$ Wealth is similarly a predictor of melanoma in England, ${ }^{15-17}$ and is not uniformly spread across the country or across ethnic groups. ${ }^{12,18}$ Using currently available national data and accounting for both skin colour and socioeconomic status as potential confounding factors, we explored regional melanoma incidence rates and latitudinal trends across England.

\section{Materials and methods}

\section{Data sources and variables}

Cancer registration in England is conducted by eight regional registries. Each registry uses standardized registration criteria set out by the United Kingdom Association of Cancer Registries for collecting data on all new primary cancer cases (recurrences and metastases not registered). ${ }^{19}$ Data collected via this system are considered to be of a high standard. Regional data at the time of collection were collated into a national database by the Office of National Statistics and then distributed accordingly by the regional registries, although national cancer registration has been adopted subsequently (from 1 April 2013) by Public Health England. ${ }^{20}$

This was an ecological study in which we obtained anonymized, individual-level, national cancer registry data from the Northern and Yorkshire Cancer Registry and Information Service (data were obtained prior to 2013) for all people in England up to 89 years of age with a primary, invasive cutaneous melanoma diagnosed between 1996 and 2006. Histology reporting is the main source (at least 95\%) for registration of new melanoma cases, and diagnostic criteria did not materially alter for invasive melanoma during the study period. In situ melanomas were excluded a priori.

Individual data on sex, age at diagnosis, location of residence at diagnosis and socioeconomic deprivation were available for each case, although ethnicity was not. Location of residence was based on postal code of residence at the time of diagnosis and categorized as one of nine Government Office Regions in England. Each region was assigned a rank (1-4) based on increasing sunlight hours - a measure often used as a proxy for ambient UV exposure $^{5}$ - from northern to southern latitude (Fig. 1), such that regions of similar latitude and sun exposure were grouped together as follows: North East (1); North West, Yorkshire and the Humber (2); East Midlands, West Midlands, East of England (3); London, South East, South West (4). Also based on postal code at diagnosis, each case's category of socioeconomic deprivation was determined using the Index of Multiple Deprivation. ${ }^{21}$ This index is a national measure of deprivation for specified geographical areas of England, based on census information, and the Income Deprivation Domain specifically captures the proportion of people in a specified area experiencing income deprivation according to means-tested benefits. ${ }^{21}$ The index consists of five ranked categories of socioeconomic deprivation ranging from 1 (least deprived) to 5 (most deprived).

Overall population estimates by skin pigmentation/ethnicity and by deprivation rank were available for each sex, age and region for only the 2001 census point in England (Population Estimates Unit, Office of National Statistics). White-only population counts were based on the combined total of those selfreporting as 'White British', 'White Irish' or 'other White' on the 2001 census. Single-year population counts in each region were extended to a 5-year interval on either side of the census point to define the study period (1996-2006).

\section{Statistical methods}

Melanoma incidence rates in each region of England were calculated by sex and by age group (10-29, 30-49, 50-69 and 70-89 years) using both the total and white-only population bases. Melanoma cases in children aged 0-9 years were excluded from our analyses $(n=31)$, as young children have a very low incidence of melanoma and a distinct disease aetiology (largely genetic rather than environmental factors implicated). ${ }^{22}$ Rates were expressed per 100000 person-years at risk and were age standardized to the European Standard Population using direct methods. ${ }^{23}$ Incidence rates by deprivation rank were also calculated for 10-29 year olds by broad geographical grouping of regions according to latitude: northern (North East, North West, Yorkshire and the Humber), central (East Midlands, West Midlands, East of England), southern (South East, South West) and London.

Poisson regression models were used to test for heterogeneity in regional melanoma incidence trends by sex, age group and deprivation level, and to estimate percentage change in incidence per unit increase in latitude rank (north to south, 1-4) and in deprivation rank (least to most, 1-5). Tests for trends with decreasing latitude across sex and age groups, and with increasing deprivation in 10-29 year olds by broad geography, were also performed. Significance was set at $\mathrm{P}<0.05$. Analyses were performed using SAS version 9.1 (SAS Institute Inc., Cary, NC, U.S.A.). 


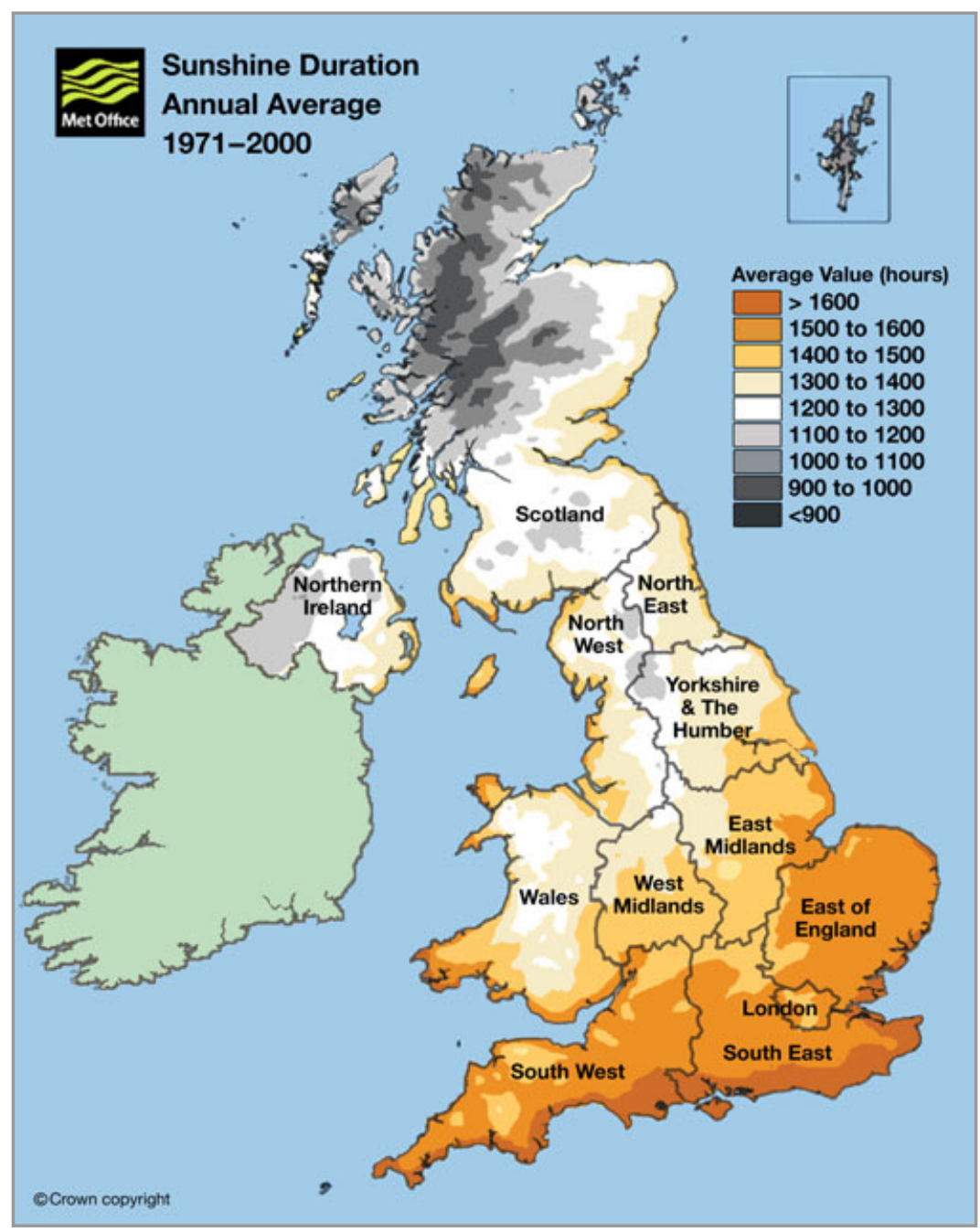

Fig 1. Average annual sunshine duration (1971-2000) across the Government Office Regions of England. Used and adapted with permission from the Met Office (C) Crown Copyright. Contains public sector information licensed under the Open Government Licence v1.

\section{Results}

Over the 11-year period of study (1996-2006), 70632 cases of invasive cutaneous melanoma (45\% male) were registered in England among people aged 10-89 years. Nearly all cases (99\%) had complete data on all variables $(n=69788)$; the $1 \%$ of cases with missing data (age, region or deprivation rank) were excluded from the analyses. The age-standardized (European Standard) melanoma incidence rates in England during this period were 13.57 per 100000 (male, 12.86; female, 14.43) among the entire population, and 14.46 per 100000 (male, 13.64; female, 15.46) in the white population (Table 1). The highest incidence in both sexes occurred in the South West (male, 18.40; female, 19.35 per 100 000), followed by the South East; the lowest rates were in London (male, 8.77; female, 9.03 per 100 000). When the denominator was restricted to the white population, incidence rates in London rose by $25 \%$ in male subjects to 10.97 per 100 000 and by nearly $30 \%$ in female subjects to 11.63 per 100 000. Smaller rises with restriction to the white population were observed in the remaining regions. Although melanoma rates in white male subjects in London briefly surpassed those in the North East (10.62 per 100 000), overall, compared with neighbouring southern regions, the London rates remained incongruously low. Overall and in both sexes, there was a significant increasing trend in melanoma rates from north to south across the country (all $\mathrm{P}<0.0001$ ), although in the white population men showed a greater percentage increase in incidence per latitude rank than women (male, $18 \cdot 1 \%$; female, $11 \cdot 1 \%$ - excluding London) (Table 1 ). Regional rates were statistically significantly different between the sexes $(\mathrm{P}<0 \cdot 0001)$.

Regional patterns of melanoma by age were investigated for the male and female (Table 2) subsets of the total and whiteonly populations, but only the latter adjusted estimates are detailed here. The percentage change estimates and trends highlighted are excluding London. In both sexes, regional rates significantly differed between the age strata (both $\mathrm{P}<0.0001)$. Melanoma incidence rates in white male subjects aged 10-29 years showed some variation across regions, from a low of 1.66 per 100000 in London to 2.47 per 100000 in the South West (Table 2). However, among the young male 


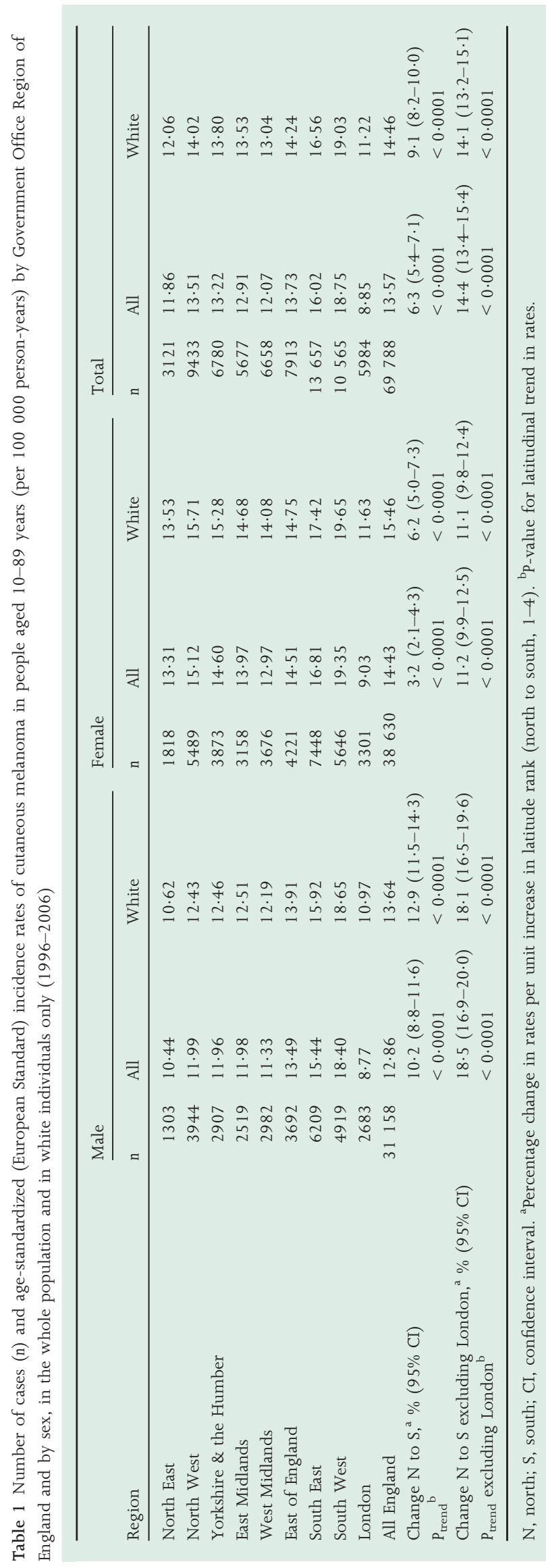

population there was no apparent latitude trend in melanoma incidence $(2 \cdot 7 \%, \mathrm{P}=0 \cdot 41)$, despite the significant negative trend overall in this age group $(-5.8 \%, \quad \mathrm{P}=0.002$; not shown). In men aged over 30 years, melanoma incidence significantly increased with more southerly latitudes: by $10 \cdot 0 \%$ per latitude rank for 30-49 year olds, by $20 \cdot 2 \%$ in those aged 50-69 years and by $23 \cdot 8 \%$ in 70-89 years olds (all $\mathrm{P}<0.0001)$.

Among 10-29-year-old white female subjects a significant trend of increasing melanoma rates with more northerly latitudes emerged, such that rates rose by $9 \cdot 8 \%$ per unit decrease in latitude rank: rates were around 3 per 100000 in London and the East of England, but 5.46 per 100000 in the North West $(\mathrm{P}<0.0001)$ (Table 2). Among 30-49 year olds, melanoma rates were similarly high at latitudinal extremes (South West, 17.69; Yorkshire and Humber, 17.25 per 100 000), and no trend was apparent $(1 \cdot 8 \%, \mathrm{P}=0 \cdot 10)$. In contrast, melanoma rates in women aged over 50 years significantly increased with more southerly latitudes, corresponding to the trends seen in older men (all $\mathrm{P}<0.0001$ ). The older age groups differed in that incidence was lowest in London $(18.18$ per 100000$)$ in 50-69 year olds, but lowest in the North East (24.62 per 100 000) for those aged 70-89 years, while the magnitude of rates was higher in the older group.

To examine the observed trends more closely in 10-29 year olds, regional melanoma rates in young people in England were examined by level of deprivation. Rates in each deprivation rank were significantly different between latitudes for the female $(P=0.002)$ and male $(P=0.02)$ subgroups. With the exception of white male subjects in the north, young people across the country showed the same trend of significantly decreased melanoma incidence with greater deprivation (Table 3). Notably, among the young white female population in the north, the second most affluent group had the highest rates of all (6.48 per 100000$)$, followed closely by the second most deprived group (5.69 per 100 000).

\section{Discussion}

In this ecological study of emerging trends of regional melanoma incidence in the English population, we observed a striking difference in latitude gradients among young people compared with older adults. The expected north-to-south increase in rates was reversed in those aged 10-29 years, driven mainly by the strong trend reversal among the young female population, particularly those of intermediate socioeconomic status. Across the remaining age groups, the northsouth increasing trend was maintained, although melanoma rates were remarkably lower in London compared with other southern regions.

Three decades ago, Swerdlow described latitude trends in melanoma incidence in England, ${ }^{3}$ but no further national studies have since been conducted. We have previously compared melanoma incidence in the Government Office Regions of England in 13-24 year olds only, and showed that in the period 1990-3, rates ranged from 10.0 (North East) to $22 \cdot 0$ 


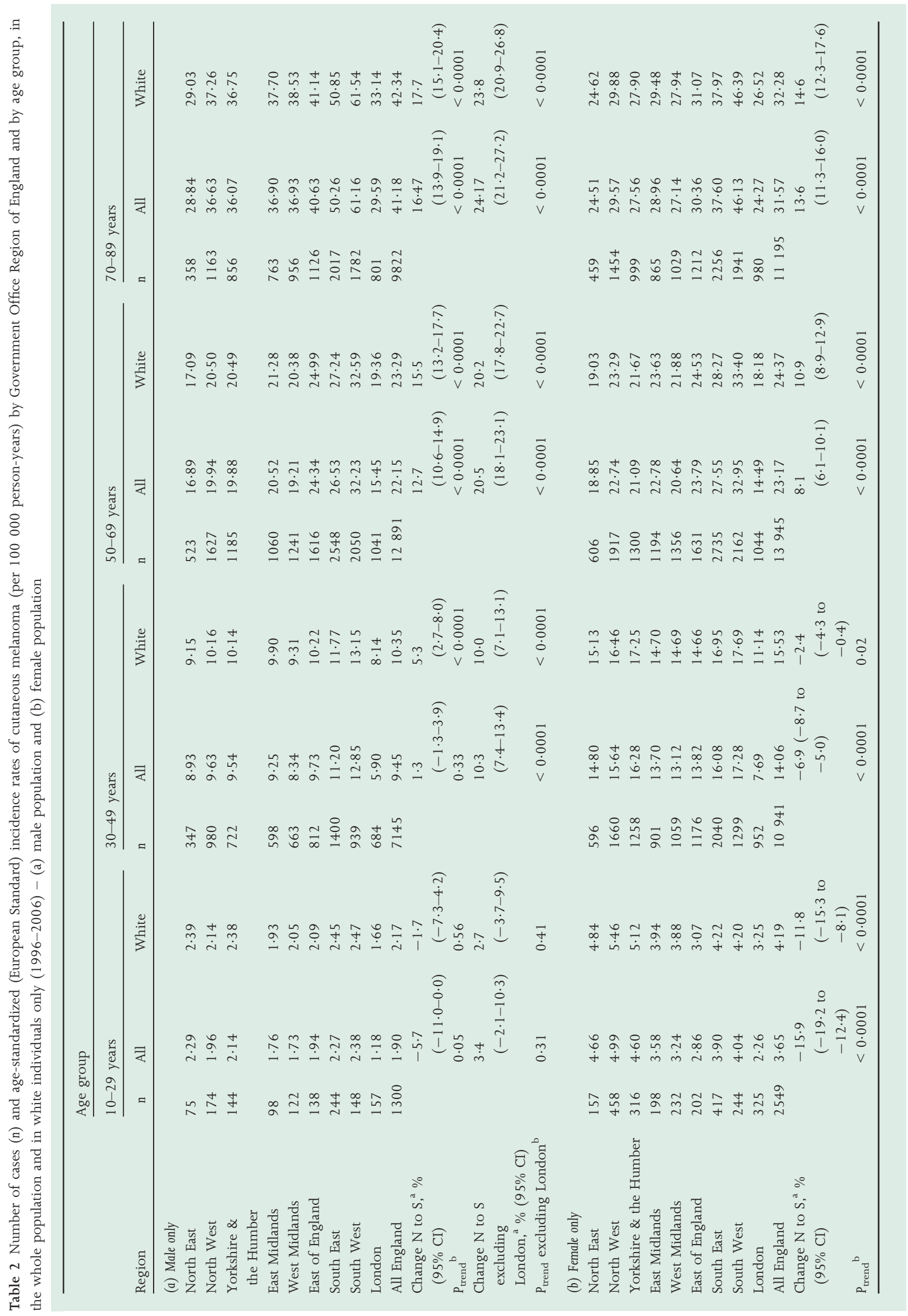




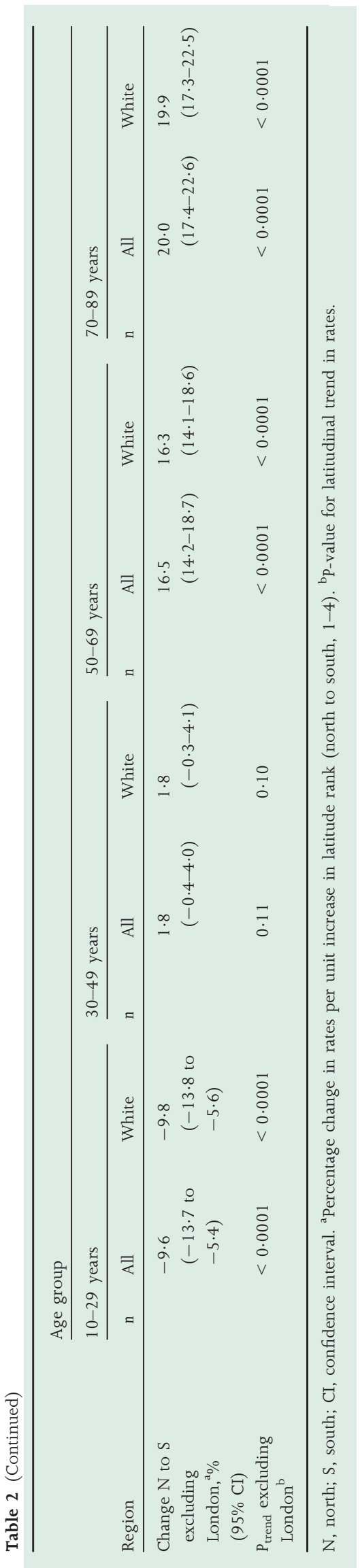

per million (South West), but a decade later rates were highest in the North West (31.0 per million) and lowest in London (11.4 per million). ${ }^{24}$ However, neither latitude nor ethnicity trends were assessed. Variations in melanoma incidence by socioeconomic status in England have previously shown rates decreasing with greater deprivation, ${ }^{16}$ results that are consistent with our own, except for our observations among young people in the north.

Several other countries in the northern hemisphere have examined melanoma latitude trends. Predominantly fairskinned populations of northern Europe, such as in Norway, ${ }^{4-6}$ have shown north-south increasing trends in incidence. Furthermore, an analysis of melanoma mortality rates in major cities across a range of latitudes in Canada and the U.S.A. demonstrated the same higher rates at more southerly latitudes. ${ }^{7}$ In contrast, a study in the Netherlands reported that melanoma rates were highest in the northern and western parts of the country, ${ }^{10}$ but the authors explained this by greater hours of sunshine and more recreational activities undertaken in coastal areas, analogous to the proposed reasons for the north-south trends elsewhere. Furthermore, in an Italian study, south-to-north increasing trends were in part explained by the predominance of the fair-hair phenotype and higher income in the north. ${ }^{9}$ While our results among older adults are consistent with previous findings, this study now points to a striking deviation from the established trend in young people, including the at-risk white population.

Changes in UV exposure, the single major cause of cutaneous melanoma, ${ }^{2}$ are likely to explain the majority of the variation in regional melanoma rates observed in this study. For older generations it has been estimated that approximately $90 \%$ of melanomas in men and $82 \%$ in women in the U.K. may be attributed to excess solar UV radiation. ${ }^{25}$ Widespread increases in recreational sun exposure along with changes in clothing fashions are major contributing factors to the rising rates of melanoma in the late twentieth century in Europe, ${ }^{5,26}$ and the previously described trend in melanoma rates in England is understood to reflect the inverse latitude gradient in ambient solar UV radiation (Fig. 1). Consistent with this explanation is the perpetuation of the strong north-south gradient we observed among those aged 50 years and over. More recent relevant changes in UV exposure over the past few decades, which may explain the general tendency for high melanoma rates in the north, include the rise in popularity of sunbeds and the advent of budget holidays. In the last 30 years, sunny holiday destinations abroad have become more affordable, and thus accessible to people of all ages and socioeconomic status, with the result that they are augmenting local sun exposure and influencing traditional patterns of sun-related skin disease. ${ }^{5,27}$ Sunbeds too are widely accessible and can provide intense UV dosages 10-15 times stronger than those obtained from midday sun exposure in a hot climate. ${ }^{28}$ They are thought to cause melanoma in up to $76 \%$ of young people who ever use them. ${ }^{29}$ In England, sunbed use has become particularly prevalent among young people, with a reported $6 \%$ of all 11-17 year olds having ever used them, 


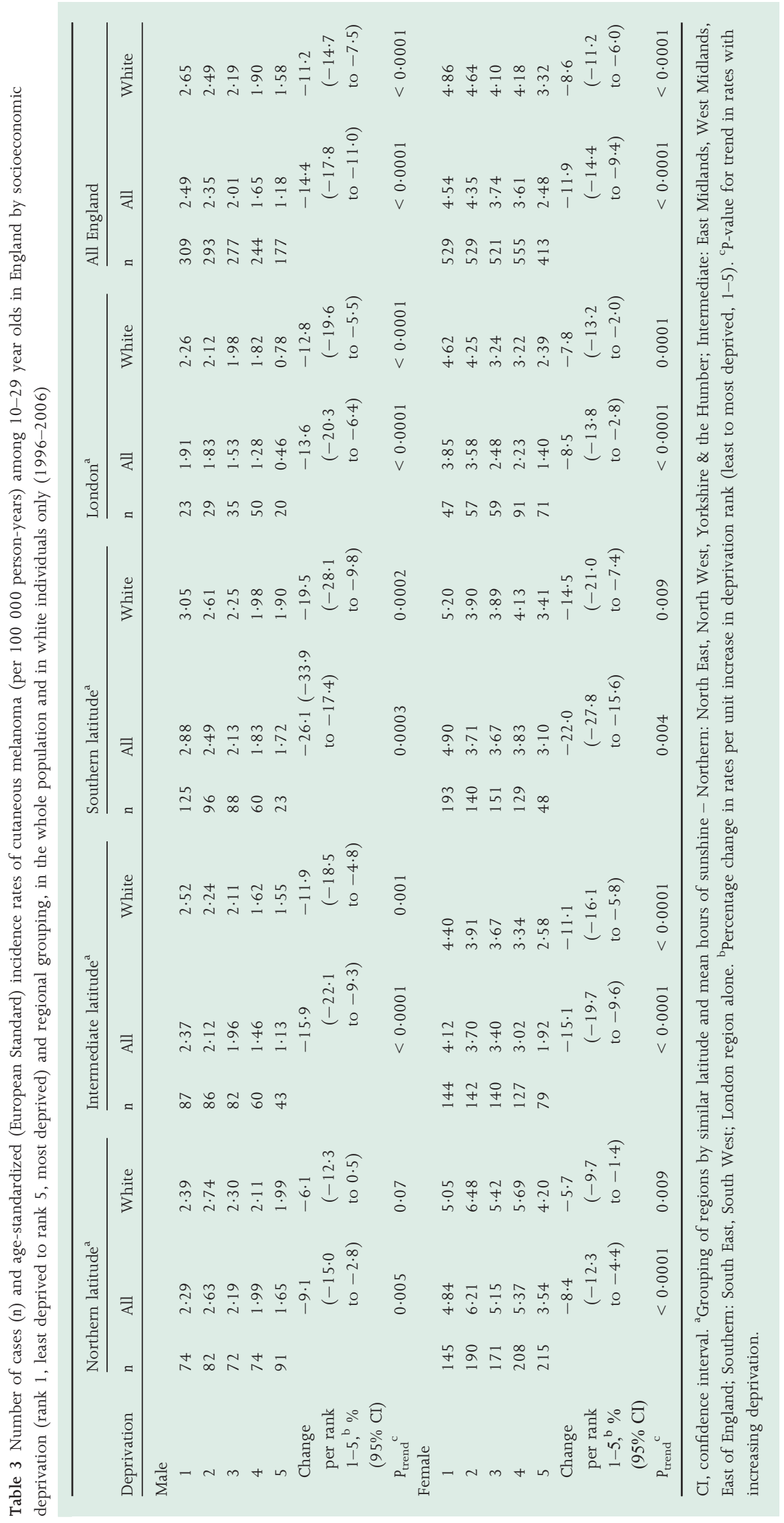


and within the country young women in the north are the most prevalent users of all (up to 50\%). ${ }^{30}$ The observed reversal of the north-south latitude gradient and peak incidence in the North West in young people are consistent with these sunbed and holiday trends, and thus appear to be the most likely explanation for our findings.

Aside from UV exposure variables, it is possible that other factors may explain some of the variation observed (i.e. phenotypic traits - hair, eye and skin colour, immunosuppression and family history). We were unable to assess these risk factors, as individual case data were unavailable, although the confounding effects of phenotypic variables, in particular, would mainly have been controlled for when the analyses were restricted to the white population.

The reason for the observed deficit of melanoma in the London region is unknown. While lack of access to sunny holidays cannot explain this observation, London's highly urban environment perhaps affords its residents less opportunity for exposure to ambient sunlight than those of neighbouring southern regions. The heterogeneity and mobility of the white population resident in London may also contribute to the unexpectedly low incidence. A further possible explanation is the low registration rate of melanomas in the Thames Registry, possibly as a result of greater use in London of private healthcare facilities where cancer data may not be readily available to registration. While cancer registration in England is highly regulated and of a high standard, some variability in data capture and efficiency of processing still remains between the regional registries. ${ }^{31,32}$

The particular strengths of this study are its relative recentness and the high quality of the data from the eight cancer registries in England. Novel strengths include accounting for both the uneven geographical distribution of low-risk nonwhite populations, and the influence of socioeconomic status in England, when considering the geographical distribution of melanoma. As this was an ecological study, the issue of 'ecological fallacy' is a possibility, as our findings are based on regional populations and cannot be inferred to individuals within these populations. We were limited in the calculation of incidence rates among white individuals as we did not have data on individual case ethnicity and thus could not restrict the numerator. The effect on our results was that some cases occurring in nonwhite subjects may have been misclassified, thereby overestimating white incidence rates. However, this should be a nearly negligible effect on our rates, as melanomas are extremely rare in nonwhite populations, ${ }^{13,14}$ and acral lentiginous melanoma, the subtype occurring most frequently in nonwhite individuals, occurs in the white population at the same relative frequency, ${ }^{33}$ so there is no differential with respect to skin colour. We also inferred the size and ethnic composition of each Government Office Region, and deprivation rank, from a single census point in 2001, a method that assumes little or consistent change in England's population structure across the study period. Notwithstanding their uneven geographical distribution, the overall proportion of nonwhites in the total population of England is small, ${ }^{34}$ and this inference method has been used previously. ${ }^{24}$ Finally, as deprivation rank is not an individual measure of income deprivation, some misclassification was possible, although it should not have differentially affected the regions.

In conclusion, although maintained in older adults, the well-established north-south increasing gradient in melanoma incidence has been reversed among young people under the age of 30 years. This significant finding was driven primarily by the reversal of latitude trends in young women, particularly in those of intermediate socioeconomic status. The affordability of sun holidays and the high prevalence of sunbed use among young adults, especially young women living in the north of England, may explain these trends. Recent banning of sunbed use in those under 18 years of age in the U.K. ${ }^{35}$ should eventually bring a reduction in harmful exposure to artificial UV in the future; however, this regulation will not completely resolve the issue as it applies only to commercial outlets, so private use remains unregulated and its effects may continue to be seen. It is important to monitor both UV exposure patterns and melanoma incidence closely in the wake of these trends and the recently implemented legislation.

\section{Acknowledgments}

We extend our gratitude to Madeleine Flynn at the Queensland Institute of Medical Research for her work on Figure 1, and to the Met Office for permission to adapt this figure.

\section{References}

1 Erdmann F, Lortet-Tieulent J, Schüz J et al. International trends in the incidence of malignant melanoma 1953-2008 - are recent generations at higher or lower risk? Int J Cancer 2013; 132:385400.

2 El Ghissassi F, Baan R, Straif K et al. A review of human carinogens - part D: radiation. Lancet Oncol 2009; 10:751-2.

3 Swerdlow AJ. Incidence of malignant melanoma of the skin in England and Wales and its relationship to sunshine. BMJ 1979; 2:1324-7.

4 Cicarma E, Juzeniene A, Porojnicu AC et al. Latitude gradient for melanoma incidence by anatomic site and gender in Norway 1966-2007. J Photochem Photobiol 2010; 101:174-8.

5 Bentham G, Aase A. Incidence of malignant melanoma of the skin in Norway 1955-1989: associations with solar ultraviolet radiation, income and holidays abroad. Int J Epidemiol 1996; 25:1132-8.

6 Micu E, Baturaite Z, Juzeniene A et al. Superficial-spreading and nodular melanomas in Norway: a comparison by body site distribution and latitude gradients. Melanoma Res 2012; 22:460-5.

7 Elwood JM, Lee JAH, Walter SD et al. Relationship of melanoma and other skin cancer mortality to latitude and ultraviolet radiation in the United States and Canada. Int J Epidemiol 1974; 3:325-32.

8 Crombie IK. Variation of melanoma incidence with latitude in North America and Europe. Br J Cancer 1979; 40:774-81.

9 Crocetti E, Buzzoni C, Chiarugi A et al. Relationship between latitude and melanoma in Italy. ISRN Oncol 2012; 2012:864680.

10 de Vries E, Schouten LJ, Visser O et al. Rising trends in the incidence of and mortality from cutaneous melanoma in the Netherlands: a Northwest to Southeast gradient? Eur J Cancer 2003; 39:1439-46. 
888 Regional trends in melanoma incidence in England, S.C. Wallingford et al.

11 Wallingford SC, Alston RD, Birch JM, Green AC. Increases in invasive melanoma in England, 1979-2006, by anatomic site. Br J Dermatol 2011; 165:859-64.

12 Tinsley J, Jacobs M. Deprivation and ethnicity in England: a regional perspective. In: Regional Trends No. 39, 2006 Edition (Phillpotts G, Causer P, eds). Basingstoke: Palgrave Macmillan, 2006; 19-28.

13 Cormier JN, Xing Y, Ding $\mathrm{M}$ et al. Ethnic differences among patients with cutaneous melanoma. Arch Intern Med 2006; 166:1907-14.

14 Winter $\mathrm{H}$, Cheng $\mathrm{KK}$, Cummins $\mathrm{C}$ et al. Cancer incidence in the south Asian population of England (1990-92). Br J Cancer 1999; 79:645-54.

15 Alston RD, Rowan S, Eden TOB et al. Cancer incidence patterns by region and socioeconomic deprivation in teenagers and young adults in England. Br J Cancer 2007; 96:1760-6.

16 Shack L, Jordan C, Thomson C et al. Variation in incidence of breast, lung and cervical cancer and malignant melanoma of skin by socioeconomic group in England. BMC Cancer 2008; 8:271.

17 Vagero D, Swerdlow AJ, Beral V. Occupation and malignant melanoma: a study based on cancer registration data in England and Wales and in Sweden. Br J Ind Med 1990; 47:317-24.

18 Whitehead M, Doran T. The north-south health divide. BMJ 2011; 342:392-3.

19 United Kingdom Association of Cancer Registries. U.K. Cancer Registration. Available at: www.ukacr.org/registration-organisation (last accessed 29 July 2013).

20 Public Health England. Available at: www.gov.uk/government/ organisations/public-health-england (last accessed 29 July 2013).

21 Neighbourhood Renewal Unit. The English Indices of Deprivation 2004: Summary (Revised). London: Office of the Deputy Prime Minister, 2004.

22 Livestro DP, Kaine EM, Michaelson JS et al. Melanoma in the young: differences and similarities with adult melanoma: a casematched controlled analysis. Cancer 2007; 110:614-24.

23 Quinn MJ, Babb PJ, Brock A et al. Cancer Trends in England and Wales 1950-1999. Studies on Medical and Population Subjects No. 66. London: The Stationery Office, 2001.
24 Alston RD, Geraci M, Eden TOB et al. Changes in cancer incidence in teenagers and young adults (ages 13 to 24 years) in England 1979 2003. Cancer 2008; 113:2807-15.

25 Parkin DM, Mesher D, Sasieni P. Cancers attributable to solar (ultraviolet) radiation exposure in the U.K. in 2010. Br J Cancer 2011; 105(Suppl. 2):S66-9.

26 de Vries E, Bray FI, Coebergh JWW et al. Changing epidemiology of malignant cutaneous melanoma in Europe 1953-1997: rising trends in incidence and mortality but recent stabilizations in Western Europe and decreases in Scandinavia. Int J Cancer 2003; 107:119-26.

27 Agredano YZ, Chan JL, Kimball RC, Kimball AB. Accessibility to air travel correlates strongly with increasing melanoma incidence. Melanoma Res 2006; 16:77-81.

28 Boniol M, Autier P, Boyle P, Gandini S. Cutaneous melanoma attributable to sunbed use: systematic review and meta-analysis. BMJ 2012; 345:e4757.

29 Cust AE, Armstrong BK, Goumas C et al. Sunbed use during adolescence and early adulthood is associated with increased risk of early-onset melanoma. Int J Cancer 2011; 128:2425-35.

30 Thomson CS, Woolnough S, Wickenden M et al. Sunbed use in children aged 11-17 in England: face to face quota sampling surveys in the National Prevalence Study and Six Cities Study. BMJ 2010; 340:c877.

31 Goodwin RG, Holme SA, Roberts DL. Variations in registration of skin cancer in the United Kingdom. Clin Exp Dermatol 2004; 29:328-30.

32 Melia J, Frost T, Graham-Brown R et al. Problems with registration of cutaneous malignant melanoma in England. Br J Cancer 1995; 72:224-8.

33 Bradford PT, Goldstein AM, McMaster ML, Tucker MA. Acral lentiginous melanoma: incidence and survival patterns in the United States, 1986-2005. Arch Dermatol 2009; 145:427-34.

34 Arora RS, Alston RD, Eden TOB et al. Cancer at ages 15-29 years: the contrasting incidence in India and England. Pediatr Blood Cancer 2010; 58:55-60.

35 Sunbeds (Regulation) Act 2010 Chapter 20. London: HMSO, 2010. 